\title{
DC protection calculations - an acceptable approach
}

\author{
R. Leach, D. Tregay \& M. Berova \\ Parsons Brinckerhoff Ltd, UK
}

\begin{abstract}
As a consequence of substantial changes to the railway track layout and implementation of a new approach to the renewal of negative bonding as part of a Major UK Railway Signalling Infrastructure Project, the need arose for reassessment of the existing electrical circuit impedances. This was necessary to ensure that circuit breakers and relays, protecting the portion of the third rail DC traction power supply network in question, had safe protection settings employed to continue to ensure safety under electrical fault conditions.

This paper outlines the challenges that needed to be overcome in gathering, processing and reconciling input data to arrive at a complete, coherent and consistent set of data necessary for the calculation of the maximum fault impedances seen from each of the circuit breakers. The paper goes on to present the development, implementation and application of the methodology for the calculation of the protection settings.

The process, illustrated with a flow-chart, was developed based on the relevant railway standards and guidance documents reflecting best practice, taking into account previous experience and the lessons learnt from other recent Power Upgrade projects. The methodology is based on modelling the feeding arrangement with an equivalent electrical circuit and was implemented into a spreadsheet based calculation tool. The tool facilitates the choice of feeding scenarios, the input and validation of data and enables sensitivity studies of the effect of various circuit components. A particular challenge of the application of this methodology and tool was the identification of the worst fault scenarios, especially in large switches and crossings areas with multiple 'Tee' feed connections at various points along the track. Such problems were solved by modelling and carrying out simulations for various scenarios to determine the worst case. The methodology and computational tool were validated for every application by comparing the results with those obtained by an independent computer programme.

The analysis of the protection setting calculation results demonstrated surprising conclusions contrary to original expectations.
\end{abstract}

Keywords: power supply, DC railway, negative bonding, protection settings, modelling, computational techniques. 


\section{Introduction}

As a result of a major re-signalling project in the UK the permanent way layout and the third rail DC traction power supply infrastructure underwent substantial change, both in terms of the switch and crossing $(\mathrm{S} \& C)$ layouts and in the plain line sections of the rail network. The installation of new types of running rails and the renewal of the traction return (negative bonding cables) based on a new technique [1] meant that existing circuit impedances needed to be revisited to ensure that circuit breakers and relays protecting the network in question had safe protection settings employed to continue to ensure safety under electrical fault conditions. This necessitated carrying out protection setting calculations for 36 electrical sections, some standard plain line and others, involving diverging routes, resulting in complex feeding arrangements.

\section{Issues relating to data}

The initial approach was to update the existing calculations, relevant to the affected electrical sections, to reflect any changes in the infrastructure. However, when compiling the data, it was found that before proceeding with any analysis there were a number of issues to resolve, namely:

- Record drawings often up to 20 years out of date or incomplete

- Recent changes arising from an earlier Traction Power Supply Upgrade project needed to be included

- Feeder cable lengths not typically included in earlier calculations where impedance values of some such feeders were actually quite significant

- Variety of protection relay and circuit breaker current tripping device types needed consideration

- Recent drawings based on metric units whereas original calculations utilised imperial units (miles and feet) thereby warranting conversion

- Mileages shown on positive (conductor rail) drawings and negative bonding drawings not always in agreement

- Details of running rail types not readily available, or unknown

- Different running rail types in parallel within electrical sections

- Multiple reference points e.g. record drawings based on miles and feet from London, permanent way drawings at switch and crossing based on local datum point, signalling drawings based on separate datum relating to extent of re-signalling project

- Changes to conductor rail cross-sections, feeder cables and return circuits arising from changes to permanent-way track layouts

\section{Selection of approach and methodology}

\subsection{Assessment of previous practice}

The existing protection setting calculations supplied by the client relating to previous stages of the traction power system development were based on simple 
hand calculations, which typically excluded cable lengths and tended to assume connection points were adjacent to the Traction Substations (TSS's) and Track Paralleling Huts (TPH's). This presented several issues to overcome:

- Hand calculations cannot readily cope with complex layouts, or multiple changes in conductor rail and running rail types.

- With hand calculations it is easy to make mistakes and difficult to check the calculations.

- Often the lengths of junctions are now typically much longer. This meant that physical connection points to conductor rails and feeder/return cables were rarely adjacent, but often a considerable distance from the TSS or TPH resulting in greater cable lengths. Therefore, it became apparent that cable impedances could not be ignored.

- Significant 'Overhangs' or 'Tee' feeds arising from extended junctions were omitted from the original calculations.

- Historically, conductor rails were of smaller cross section, hence impedance was very similar to the feeder cables and actual connection point was not considered particularly critical.

Figures 1-3 below show the variety of configurations as typically found on most schemes of this kind.

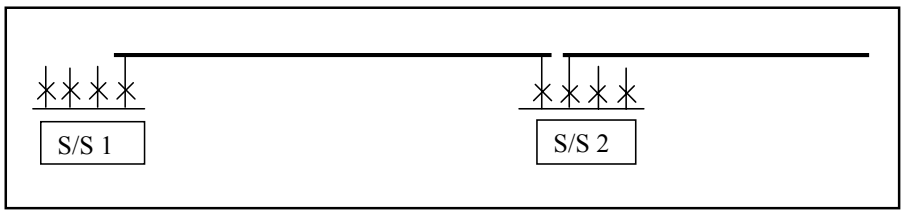

Figure 1: Normal feeding (no 'Tee' feed or 'Overhang').

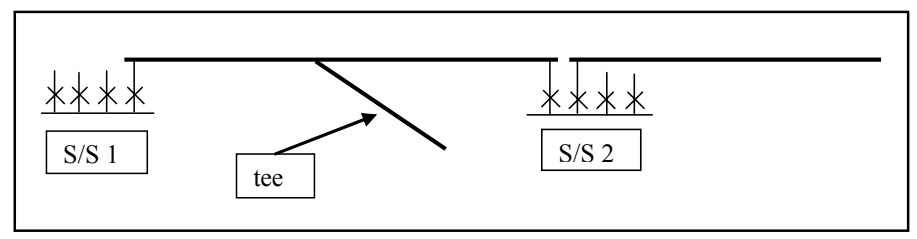

Figure 2: $\quad$ Branch in section forms a 'Tee' feed.

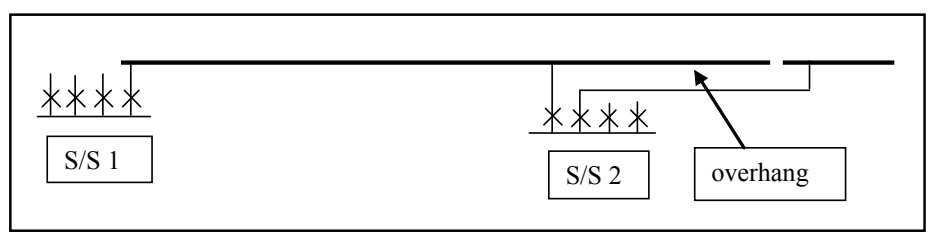

Figure 3: 'Overhang' with connections remote from substation. 
Note: A 'Tee' feed or 'Overhang' (which is equivalent to a 'Tee' feed in electrical circuit terms) is particularly difficult to evaluate in terms of providing suitable protection settings. This arises as a fault in the 'Tee' or 'overhang' results in fault current from the two feeding circuit breakers flowing along the same path, thereby increasing the apparent impedance seen by the circuit breakers. It is therefore necessary to determine whether a fault at the end of the 'Tee', or a fault at the remote end of the section represents the higher impedance, in order to determine the required settings (see Figs. 2 and 3). The risk is that neither circuit breaker may trip under a fault condition.

\subsection{Selected approach}

As a consequence of the above, it was decided that hand calculations were not appropriate for this project. Instead, the process was undertaken through use of a calculation spreadsheet (PB-ProCalc) with data inputted via a customised front end template, incorporating the relevant formulae contained within Sections 8.3 and 8.7 of the client's process document [3]. The calculations were also modified to take account of the client's specific requirements within the guidance document [4].

The main changes from the clients process document are clearly defined in his guidance note [4]. The designer is instructed to exclude any allowance for rail joints and bonding resistances. A 7.5\% tolerance is to be added to the settings to compensate for impedance relay tolerances. Any cables over $15 \mathrm{~m}$ in length are to be separately identified and included in the calculations.

In order to validate the accuracy of the spreadsheet, a full check of the formulae within the spreadsheet was carried out using an independent Engineer within Parsons Brinckerhoff (PB). In addition, the spreadsheet was tested against one of the worked examples in the clients process document [3] and against the example 'Tee' feed calculation results contained in the clients Guidance document [4]. As a further means of verifying the accuracy of the spreadsheet, a second independent set of calculations were undertaken using Network Rail 'Tee' feed computer program [5] for all of the electrical sections on the project.

The Proposed Approach was documented [6] and submitted to the client, and formal acceptance received prior to implementation.

\subsection{Modelling}

An equivalent circuit was created for each electrical section based on information derived from design drawings and record drawings (see section 4 and the Flow Chart in Figure 6 for further details).

In order to simplify the calculation process, and to arrive at worst case, the following rules were applied:

- Benefits of reinforcement cabling for running rails around S\&C locations and at single rail track circuited areas were excluded from calculations as worst case, on assumption these could be disconnected during maintenance, etc. and therefore not available for traction return. 
- Running rails were assumed to be $109 \mathrm{lb} / \mathrm{yd}$ (smallest cross section) throughout as per original, unless confirmed otherwise.

- Conductor rail also assumed to have the smallest cross section $(100 \mathrm{lb} / \mathrm{yd})$, unless confirmed otherwise.

- In order to simplify calculations in multi-track areas, where different types of running rail are in parallel, a particular rail size was selected and the length adjusted in the spreadsheet to provide an equivalent impedance.

- Cable lengths to substations and TP Huts were typically scaled from the conductor rail and negative layout drawings as exact cable lengths were not typically available.

- 'Tee' points and 'Overhangs' were worked out separately for positive and negative circuits, making the calculations simpler to handle. This produced exactly the same result as if the elements were combined.

\subsection{Methodology}

The preparation of equivalent circuits for the positive side (conductor rails) became relatively straightforward, although determination of actual connection points was in some cases difficult due to imprecise record data for some areas. The situation with regard to the negative return circuits was, however, often quite complex.

In some instances it was far from clear which equivalent circuit should be used for the return circuit, in particular relating to multi-track areas with substation return connections at differing points for each track (sometimes hundreds of metres apart) and potentially involving an 'overhang' situation. The dilemma was how to determine the position/length of the 'overhang' in relation to the equivalent circuit for the remainder of the main line in terms of whether a single point for all the return connections should be assumed, or each track worked out separately. If a single point of connection is assumed, the issue arises of where it should be placed: at the electrical mid-point for instance; at the closest connection point; or at the furthest point from the substation. All of these options then impact on the length of the assumed 'overhang', so in the end it was decided that all of these options should be tested and the worst case taken.

Figures 4 and 5 below illustrate two extremes at the end of an electrical section, with a fault occurring just beyond the substation return connections. The solid lines are assumed to be part of the fault path and included in the calculations, whereas the dashed lines are excluded. The dashed vertical line indicates the assumed return connection point to the tracks.

\section{Detailed process}

The process of carrying out the protection setting calculations is presented in the Flow Chart illustration, Fig. 6 below. 


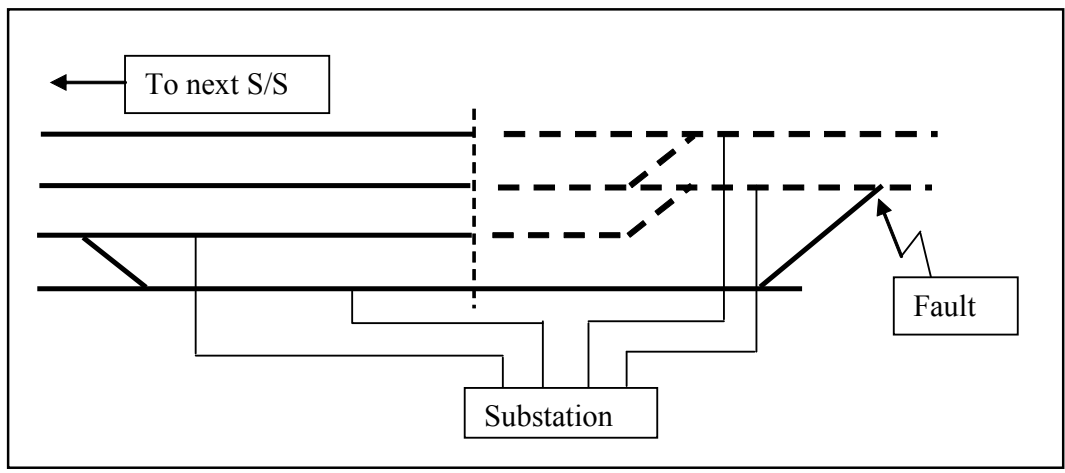

Figure 4: Return connections to rail taken as electrical mid-point 'along track' position.

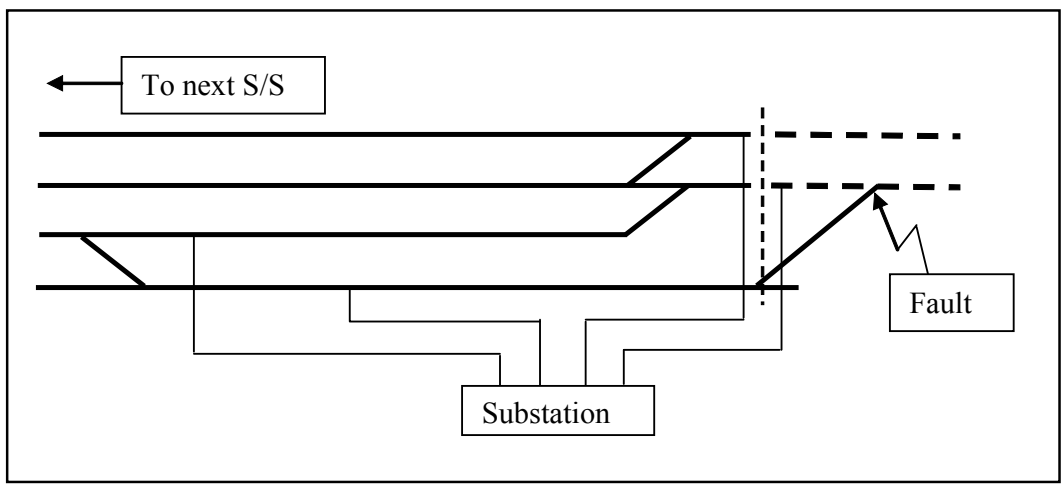

Figure 5: Return rail connections taken at the furthest negative return connections in the electrical section.

\subsection{Preparation of single track schematic diagram}

A single track schematic diagram (Fig 7) of the positive and negative circuits was prepared and marked up with all the information necessary for the definition of the geometry, circuit elements (sections of rail(s), or cables) and their dimensions and parameters, i.e. circuit references, boundaries, mileage of important points, rail types, cable sizes, points of change of rail type and identification of the circuit elements together with their respective lengths. The physical circuit diagram was then used to derive the feeding arrangement diagram (Fig 8), which was in turn converted into equivalent electrical circuit diagram (Fig 9). The first diagram indicated the absence or presence of 'Tee' feed in the positive and/or negative circuits, left-hand or right-hand 'Tee' feed, whilst the second identified the equivalent circuit components, used as input data to the calculation spreadsheet summarised in Table 1. For the purpose of 


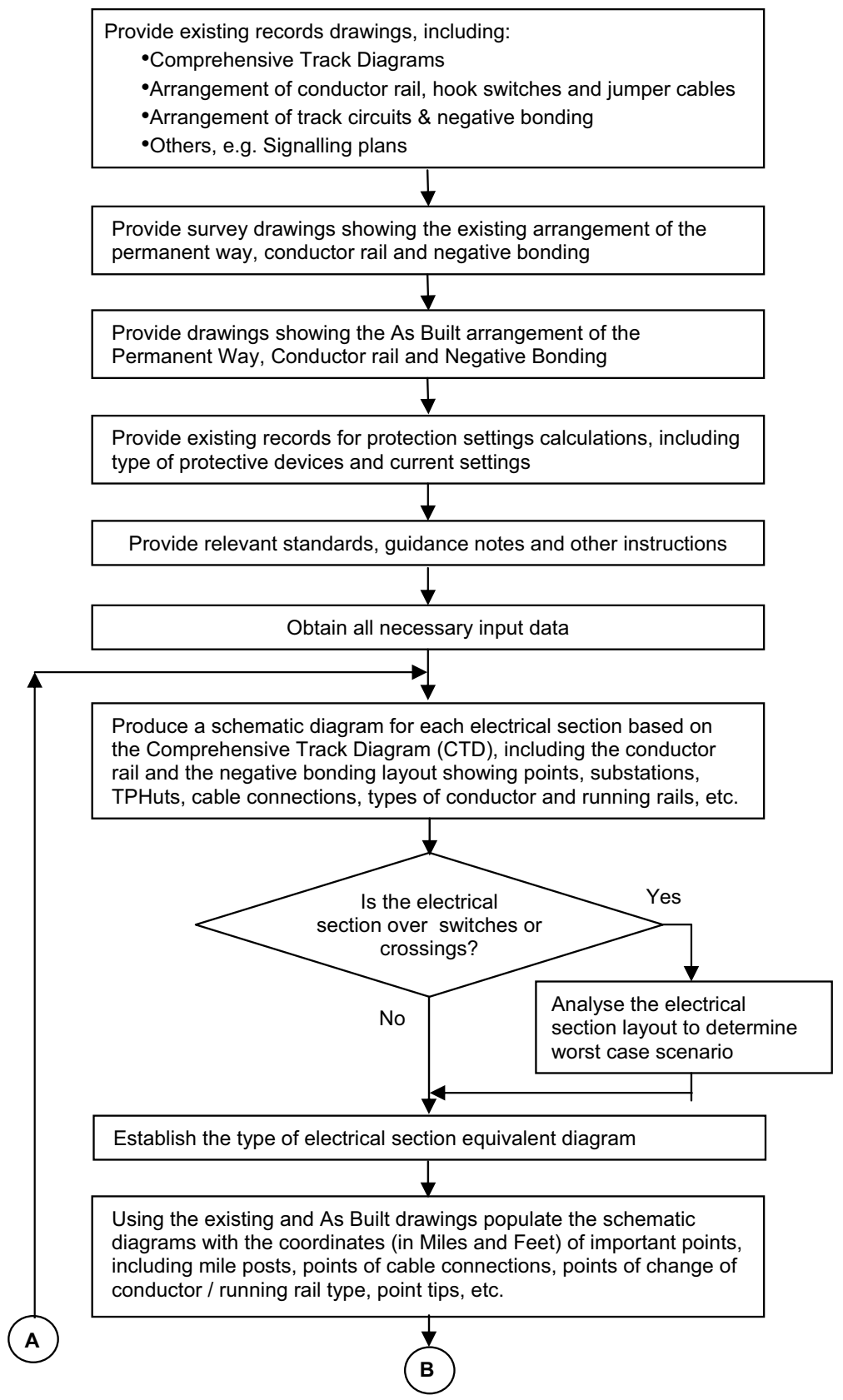

Figure 6: Flow-chart of the protection setting calculation process for Tee feed case (in plain line feeding case latter comparison stage omitted). 


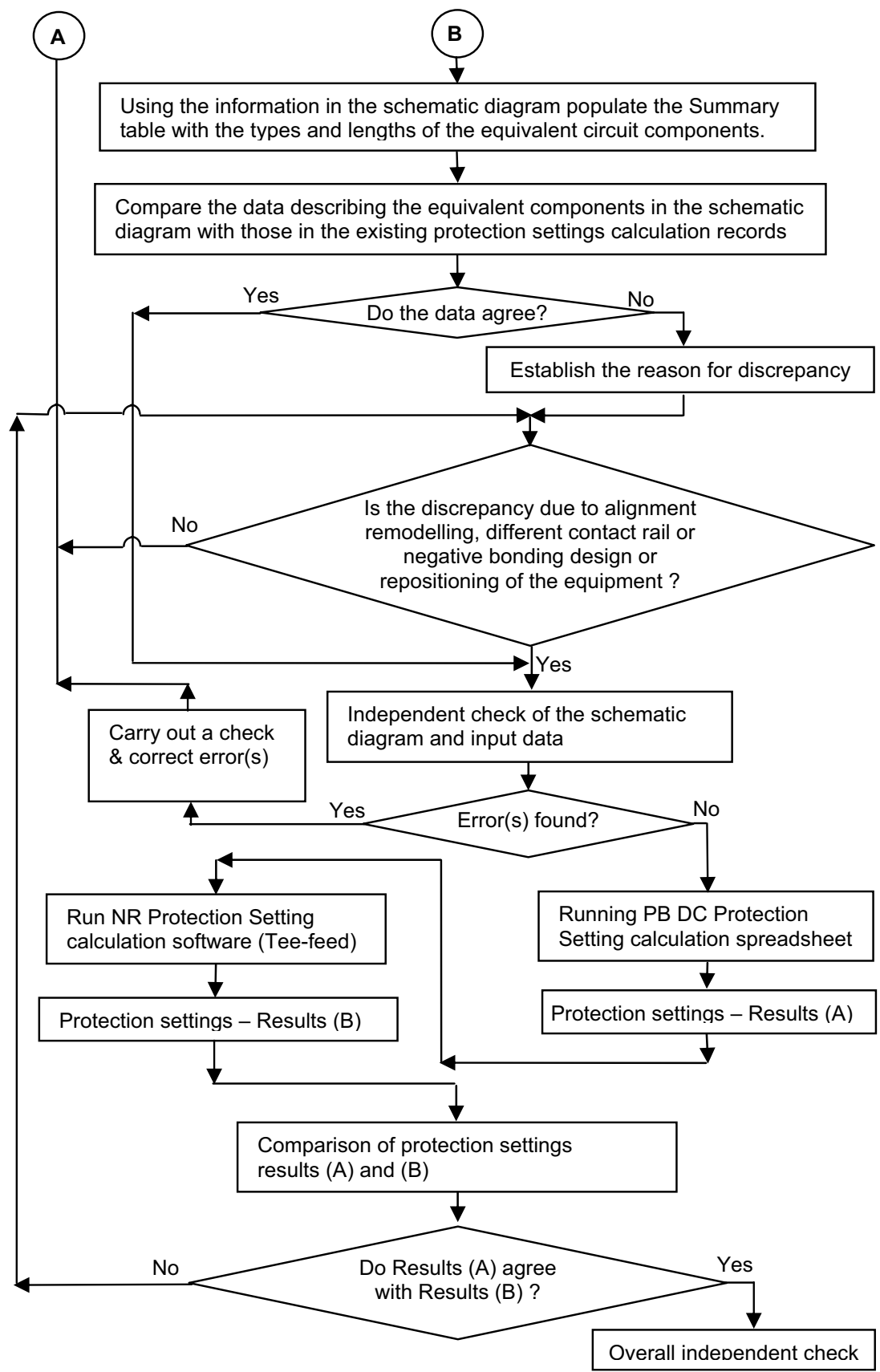

Figure 6: Continued. 


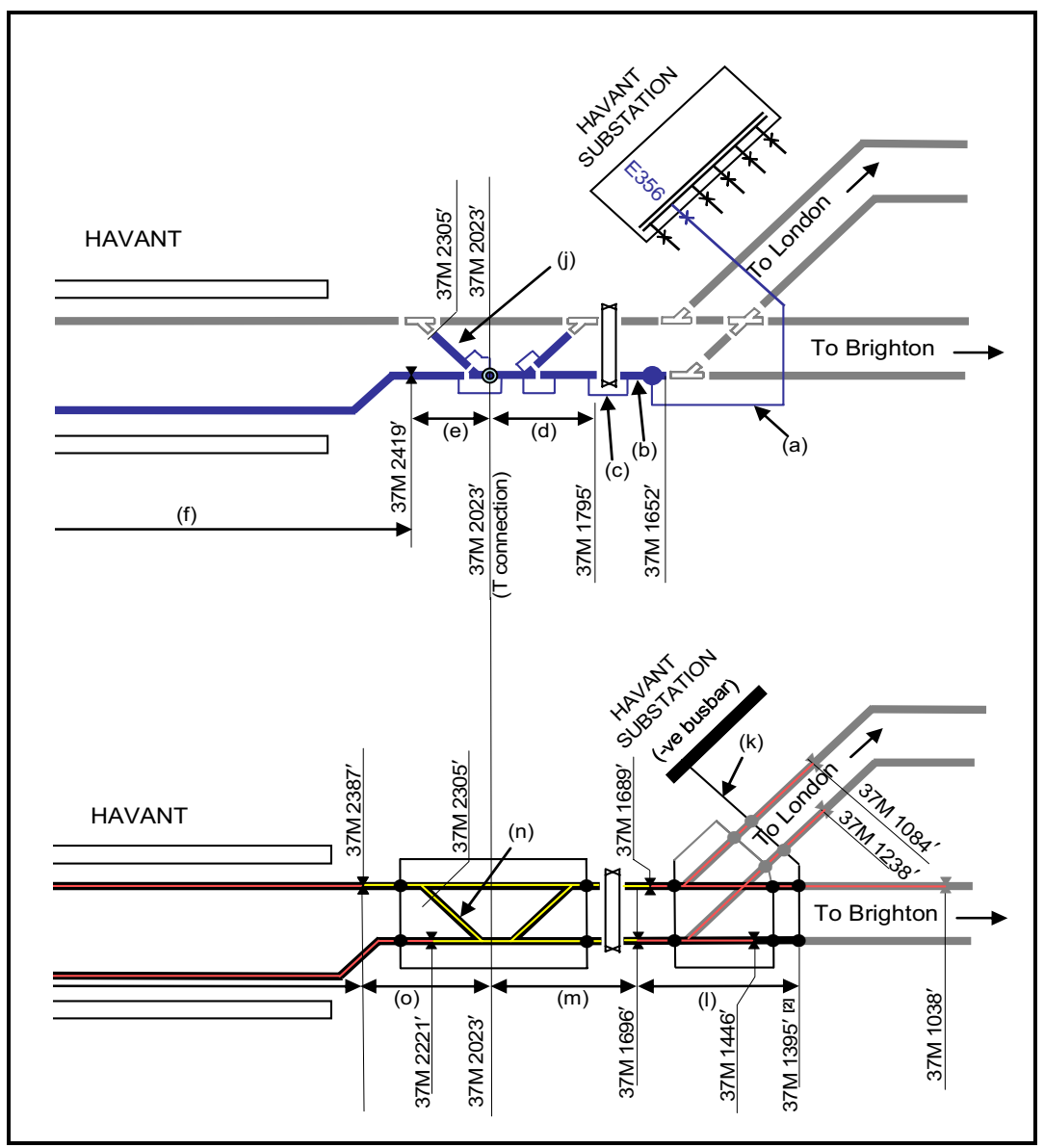

Figure 7: Extract from a track schematic diagram of the traction power supply system.

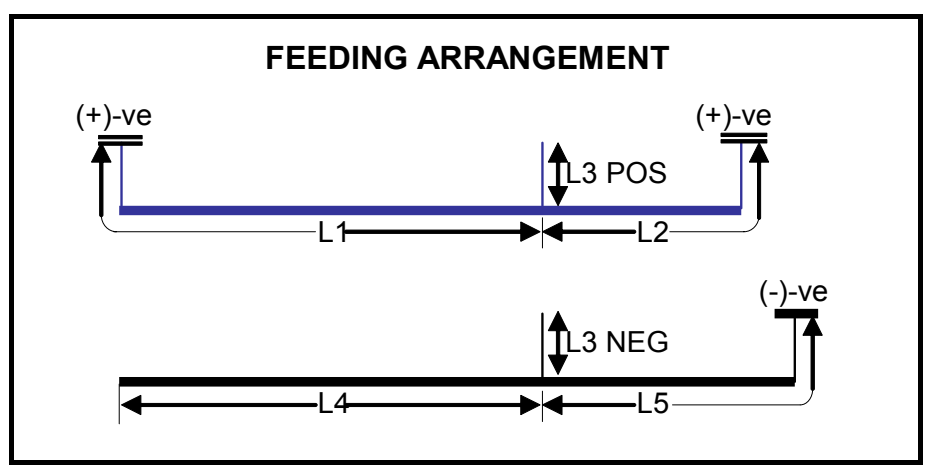

Figure 8: Electrical section feeding arrangement. 


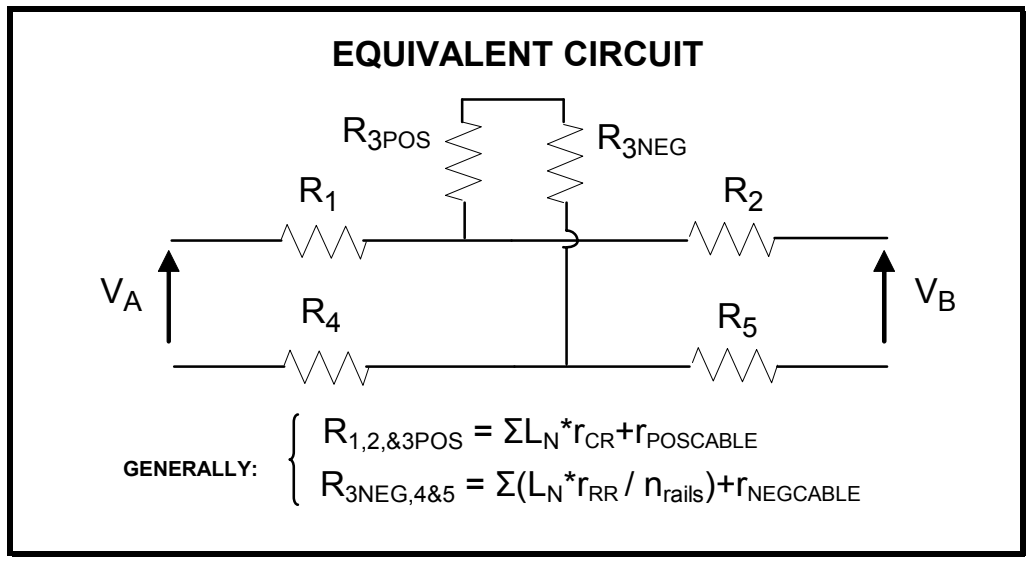

Figure 9: Electrical section equivalent diagram.

Table 1: $\quad$ Extract from input data summary table.

\begin{tabular}{|c|c|c|c|c|}
\hline $\begin{array}{l}\text { Equivalent } \\
\text { Circuit } \\
\text { Component }\end{array}$ & Ref. & $\begin{array}{l}\text { Type of circuit elements } \\
\text { (cable/rail) }\end{array}$ & $\begin{array}{l}\text { Length } \\
\text { (feet) }\end{array}$ & $\begin{array}{l}\text { Total } \\
\text { length } \\
\text { (feet) }\end{array}$ \\
\hline \multirow{4}{*}{$\mathrm{L}_{2}$} & \multirow{2}{*}{$\begin{array}{l}\text { (a) } \\
\text { (c) }\end{array}$} & Cable type 'z' & 500 & \multirow{2}{*}{600} \\
\hline & & Cable type ' $z$ ' & 100 & \\
\hline & (b) & Conductor rail type $150 \mathrm{lb} / \mathrm{yd}$ & 79 & \multirow{2}{*}{307} \\
\hline & (d) & Conductor rail type $150 \mathrm{lb} / \mathrm{yd}$ & 228 & \\
\hline $\mathrm{L}_{3 \text { POS }}$ & (j) & Conductor rail type $150 \mathrm{lb} / \mathrm{yd}$ & 282 & 282 \\
\hline $\mathrm{L}_{3 \mathrm{NEG}}$ & (n) & $2 \times$ Running rail type CEN60E1 & 282 & 282 \\
\hline \multirow{3}{*}{$\mathrm{L}_{5}$} & $(\mathrm{k})$ & 4 x Cable type 'a' & 150 & 150 \\
\hline & (1) & $4 \times$ Running rail type BS113A & 301 & 301 \\
\hline & (m) & $4 \times$ Running rail type CEN60E1 & 328 & 327 \\
\hline
\end{tabular}

traceability and clarity the schematic diagram contained a list of all the source drawings and documents from which the data has been extracted, together with any assumptions made.

\subsection{Calculation of fault impedances}

Following the input of data from Table 1 to the Calculation Spreadsheet (PBProCalc), the sheet automatically determines if a 'Tee' feed exists or otherwise and proceeds to compute the fault impedance seen by each circuit breaker feeding each electrical section (A and B) of the two track railway (in the example given). The result can be seen from Fig 10. 


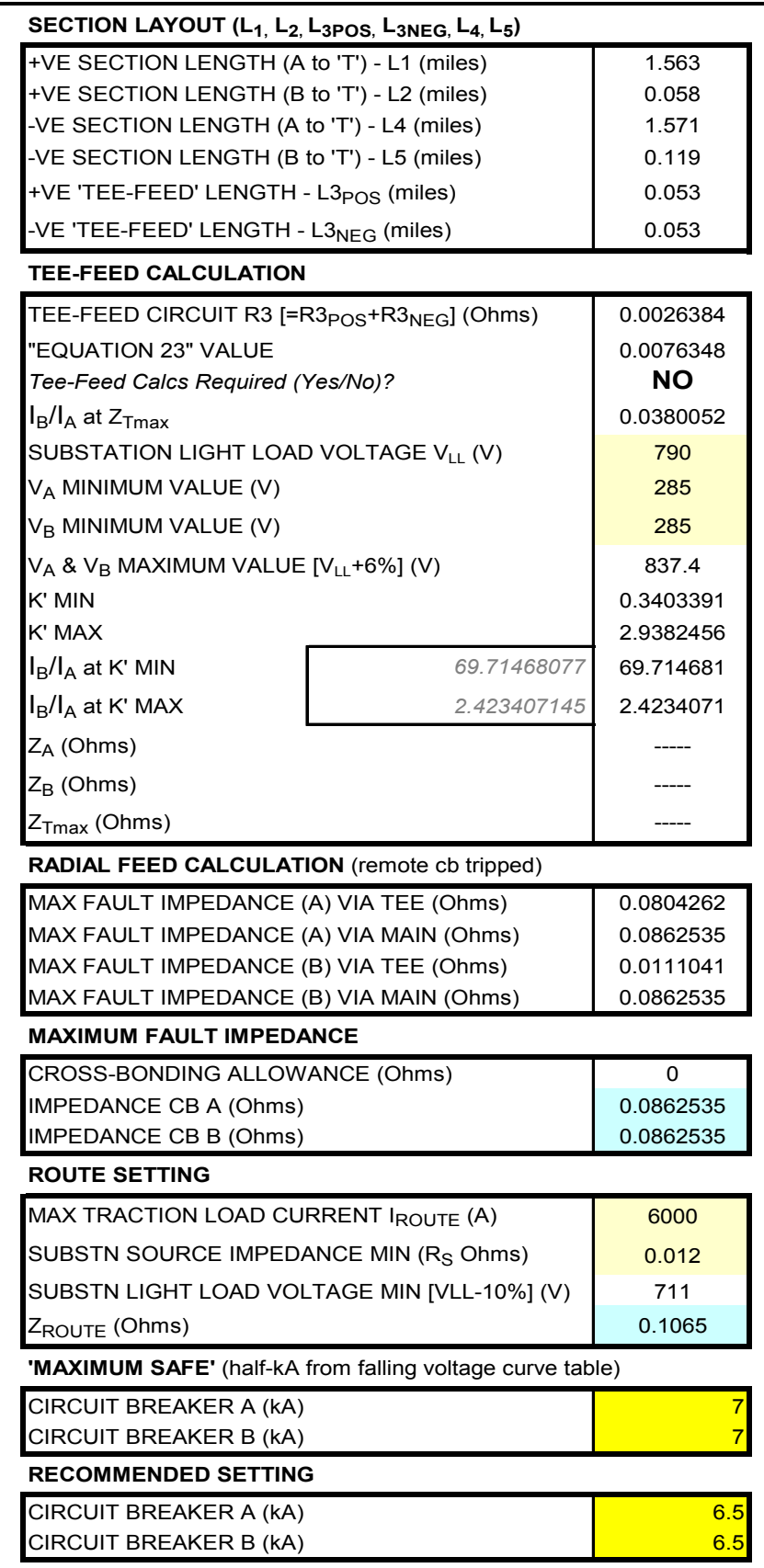

Figure 10: Extract from Protection Setting Calculations Spreadsheet (PBProCalc) illustrating the calculation of fault impedances and protection settings. 


\subsection{Derivation of protection settings}

Impedance relays and Falling Voltage Overcurrent protection were the two types of DC traction feeder protection that existed on the portion of infrastructure involving this project.

\subsubsection{Impedance relays}

- For impedance type relays, 7.5\% was added to the value derived in the box headed 'Maximum Fault Impedance' to determine the actual figure ('Maximum Safe') to be used for the settings.

- Recommended Settings were then derived manually by rounding up to the next $2.5 \mathrm{~m} \Omega$, but in any event to be no more than $20 \%$ higher than those given for 'Maximum Safe' setting to ensure proper discrimination with the circuit breakers feeding the next electrical section.

- In order to avoid unnecessarily changing existing settings, where the existing setting is between 'Maximum Safe' and 20\% above 'Maximum Safe', then the recommendation has been to leave the setting unchanged

- Additionally a Direct Acting Overcurrent Electromagnetic Trip is set at a higher 'common' setting to cater for close up faults.

\subsubsection{Falling Voltage Overcurrent protection}

In the case of Falling Voltage Overcurrent protection which is principally an electromagnetic device mounted within and forming part of the mechanism of a DC circuit breaker, the settings were derived by converting the manufacturer's standard protection curves to an impedance table (Fig 11) showing settings (kA) against impedance. The actual 'Maximum Safe' setting is determined by taking the impedance value from the calculation spreadsheet i.e. 'Maximum Fault Impedance' and then reading off the required setting in $\mathrm{kA}$ (rounded down to next $\mathrm{kA}$ value on the chart if the impedance is mid way between settings).

\subsubsection{Route setting}

This is the setting required on a particular electrical section which will allow train services to operate without resulting in 'nuisance tripping' and is normally advised by the client. Any settings should normally be above this value.

\subsubsection{Summarising of results}

The settings required for all of the electrical sections between adjacent substations (or substation and TP Hut) were then summarised on A4 sheets, in order that all the information relevant to those sections was available from one sheet. In all cases 'Category 1' safe settings were achieved (based on worst case data and feeding arrangements, hence not requiring any operational restrictions).

\section{Discussion and conclusions}

It was originally thought that the enhancements and reinforcement to the negative bonding arrangements as described in [1], together with changes to 


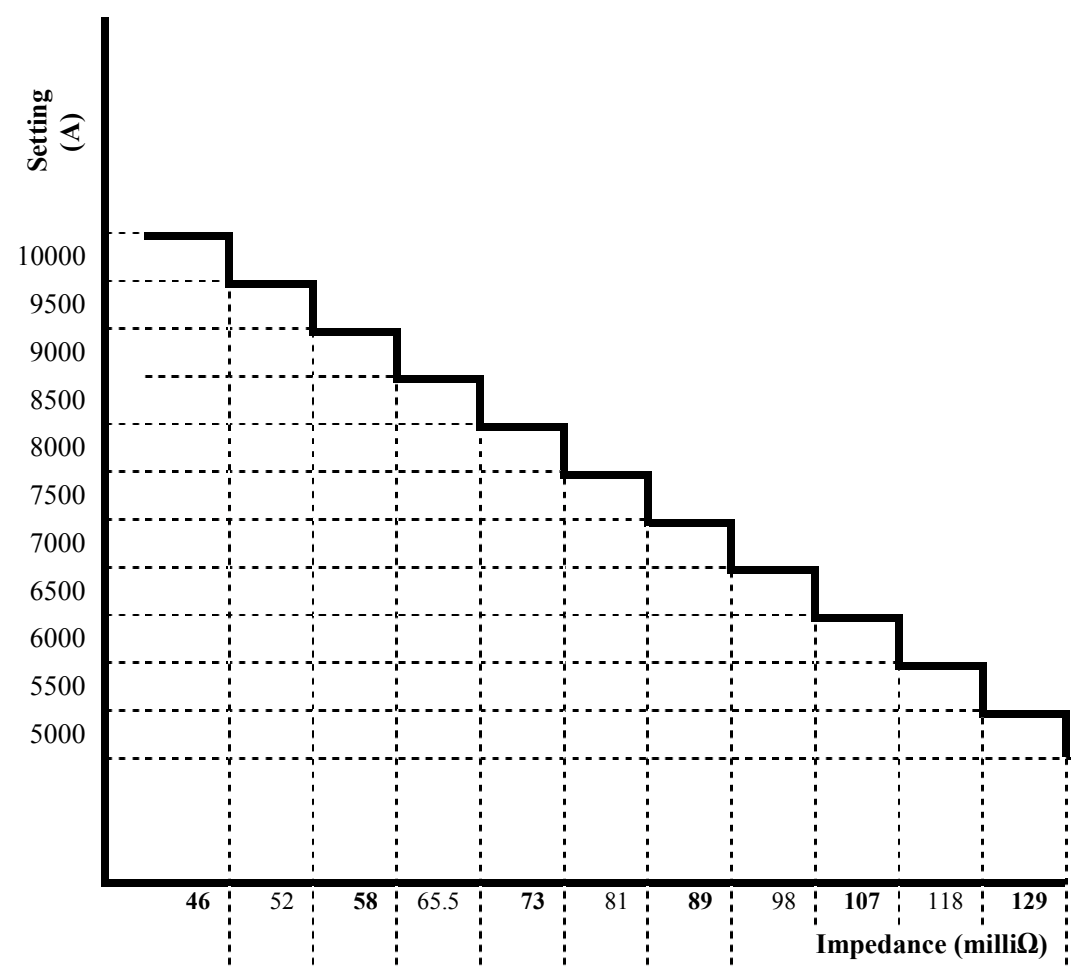

Figure 11: Chart of Overcurrent Settings versus Impedance including half (kA) settings (for circuit breaker type RJR530L).

conductor rail size, would logically lower the associated electrical impedances in comparison to the existing infrastructure. Benefits may have been realised in the form of allowing increases in (current based) protection settings, thus permitting higher train currents in section. However, the overall impact was seen to be minimal. This was due to a range of factors which included modifications to the S\&C layout and associated detailed electrical feeding arrangements, together with the application of the methodology contained in the client's process document. This was further supplemented by the corresponding guidance note [4], namely working within the parameters of $7.5 \%$ when undertaking the calculations, thus allowing retention of many existing settings. If one was to stay within parameters of $2.5 \%$, as suggested by [3] then definite changes would have been warranted.

Consequently, the resultant sensitivity of the calculations to the actual negative bonding reinforcement was seen to be relatively low. Moreover, the majority of settings calculated were noted as being close to existing and therefore not necessitating any changes. Only in a few instances were recommendations made to change settings (calculated impedances actually increased). Although no major changes were perceived, this exercise was still seen to be of great benefit in that it provides a solid basis for future applications 
when ascertaining these types of protection settings. This approach was considered pragmatic gave a scientific means of calibration between the spreadsheet mathematics and software. Moreover, the method allows for further refinement and development as changes take place in the future.

\section{Acknowledgements}

The authors would like to thank Network Rail for their permission to publish this paper.

The support of Thomas Palfreyman, Head of Electrification, PB Ltd in developing this calculation process and spreadsheet, and in reviewing this paper, is also recognised.

\section{References}

[1] Development of an Improved Traction Return System, Eur Ing Raymond Leach and Dennis Tregay, paper Railway Engineering - 2007, $9^{\text {th }}$ International Conference, London, UK, 20/21 June 2007.

[2] NR/SP/ELP/21051 'Calculation of Protection Settings for DC Circuit Breakers', Issue 2 dated Dec.2005

[3] NR/GN/ELP/27006 'Calculation of Protection Settings for DC Track Feeders, Issue 2 dated April 2006

[4] Network Rail Southern Region Power Supply Upgrade Project - Guidance Note A437-00-DC-32031 'DC Protection Setting Calculation', Issue C1.0 dated 11 May 2004

[5] Network Rail Computer Programme "RUN FILE DC3.EXE"

[6] Parsons Brinckerhoff (PB) Methodology for Undertaking Protection Setting Calculations associated with re-modelling and negative bonding changes (Issue 1 dated 07/09/06) 